\title{
Contact Thermal Analysis and Wear Simulation of a Brake Block
}

\author{
Nándor Békési and Károly Váradi \\ Department of Machine and Product Design, Budapest University of Technology and Economics, Müegyetem rkp. 3, \\ H-1111 Budapest, Hungary \\ Correspondence should be addressed to Nándor Békési; bekesi.nandor@gt3.bme.hu
}

Received 11 October 2012; Accepted 23 January 2013

Academic Editor: Patrick De Baets

Copyright ( 92013 N. Békési and K. Váradi. This is an open access article distributed under the Creative Commons Attribution License, which permits unrestricted use, distribution, and reproduction in any medium, provided the original work is properly cited.

\begin{abstract}
The present paper describes an experimental test and a coupled contact-thermal-wear analysis of a railway wheel/brake block system through the braking process. During the test, the friction, the generated heat, and the wear were evaluated. It was found that the contact between the brake block and the wheel occurs in relatively small and slowly moving hot spots, caused by the wear and the thermal effects. A coupled simulation method was developed including numerical frictional contact, transient thermal and incremental wear calculations. In the $3 \mathrm{D}$ simulation, the effects of the friction, the thermal expansion, the wear, and the temperature-dependent material properties were also considered. A good agreement was found between the results of the test and the calculations, both for the thermal and wear results. The proposed method is suitable for modelling the slowly oscillating wear caused by the thermal expansions in the contact area.
\end{abstract}

\section{Introduction}

Applications with dry sliding friction between metal parts are common in classical mechanical engineering practice $[1,2]$. However, the processes in railway brake systems are quite complex. There are many studies about the steadystate friction of such applications, some of them considering even the wear and the thermal effects [3-6]; yet the real-life braking is typically a transient phenomenon, the vehicle is usually stopped in seconds or in a few minutes. Since most of the kinetic energy of the train is transferred to heat by the friction between the wheels and the brake blocks, a big amount of heat is developing in a short time. It was found earlier that in the beginning of the braking, the edges of the brake blocks contact the wheel, even when the brake block is worn. This can be explained by the thermal expansion of the brake blocks: at the end of the previous braking, the brake block is worn, so the radii of the wheel and the brake block approximately are equal. Then, the system cools down, and since there is a great decrease in temperature, a significant thermal deformation occurs, which causes the brake block to have a shape that fits the wheel only at the edges. There is another interesting feature that is called thermoelastic instability (TEI) in the literature, which is responsible for the appearance and moving of hot spots in the apparent contact area. The TEI was investigated in a number of papers (e.g., in [7-11]), and it was found to be caused by the joint effect of wear and thermal expansion of the high-temperature hot spots.

present paper shows experimental and numerical analysis of the thermal and tribological processes of the wheel/brake block system during braking, particularly in the running-in phase.

\section{Experimental}

In order to cast light on the processes during braking, a wear test was performed at the Department of Railway Vehicles and Vehicle System Analysis (Budapest University of Technology and Economics, Budapest, Hungary) on a 1:4 scaled test rig. In the experimental setup, a brake block was pressed against a rotating wheel (Figure 1).

2.1. The Wear Test Parameters. Within the frame of this research, our main goal was to understand the phenomena 


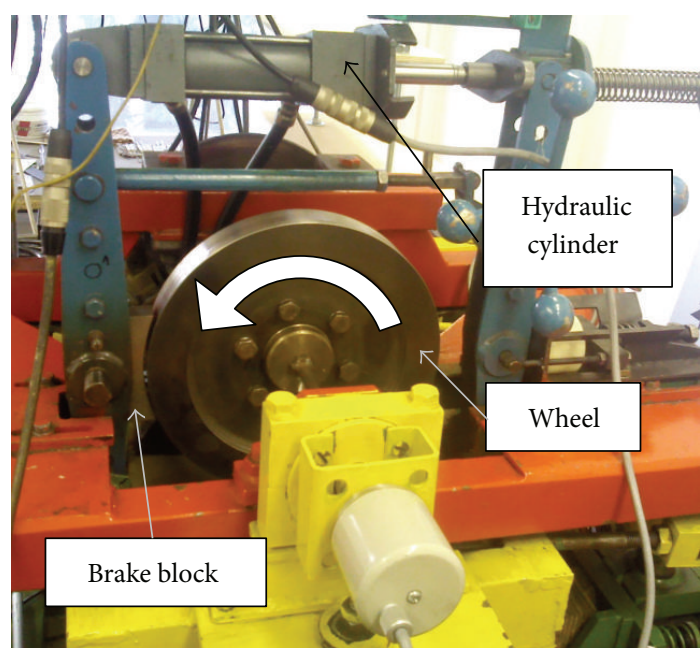

FIGURE 1: The test rig.

occurring in the running-in phase of the braking process; therefore, the total time of the test was $50 \mathrm{~s}$. The normal and the frictional force was measured by load cells and registered during the test.

The brake block was $92 \mathrm{~mm}$ high, $20 \mathrm{~mm}$ wide, and its initial radius was $119 \mathrm{~mm}$ (Figure 2). The wheel is $35 \mathrm{~mm}$ wide; its radius is $121 \mathrm{~mm}$. The brake block was pressed against the wheel with a normal force of $500 \mathrm{~N}$ by a hydraulic cylinder. The wheel was rotating at $875 \mathrm{rpm}$, so the sliding velocity was $40 \mathrm{~km} / \mathrm{h}$. The rotational speed of the wheel and the normal force were kept constant during the test.

The heating of the brake block was observed by three thermocouples. The thermocouples were fitted in holes $5 \mathrm{~mm}$ under the surface in the brake block at the positions indicated in Figure 2. The temperature data were registered during the test online. The temperature of the wheel was measured three times (at $0 \mathrm{~s}, 25 \mathrm{~s}$, and $50 \mathrm{~s}$ ) by a laser thermometer (Advanced ThermoLaser TMTL $1400 \mathrm{~K}$, SKF, Sweden). The thermometer was calibrated for the front face of the stationary wheel before the test, then the temperature was measured on the same spot of the rotating wheel.

2.2. Results of the Wear Test. Figure 3 shows the worn surface of the brake block after the test. It can be seen that the wear of the brake block is limited to the two contact areas at the two edges and furthermore that the wear is not symmetric: the wear on the left side (at the leading edge) is slightly higher than that on the right side (at the trailing edge). The asymmetry of the wear pattern was caused by the friction: the contact pressure distribution was asymmetric due to the friction and so was the wear intensity of the brake block. This phenomenon is well known and is responsible for the pivoting of the brake block on the pin.

The measured coefficient of friction was 0.38 .

The temperature of the measured points versus time is shown in Figure 4. It can be seen that the two edges of the brake block heat up quickly since these are close to the contact zones, while the measured point in the middle is heated less
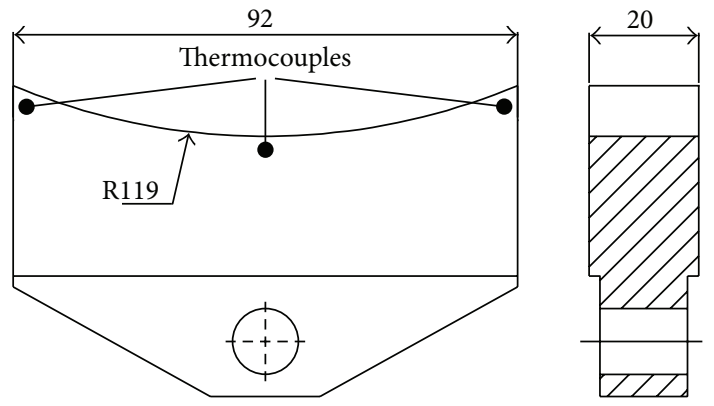

FIgURE 2: The main dimensions of the brake block.

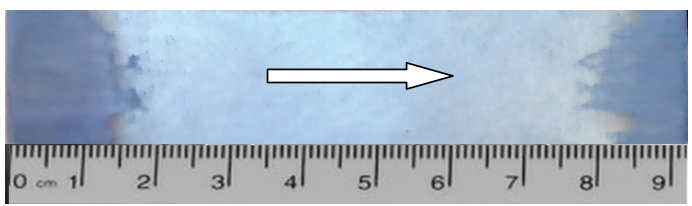

Figure 3: The worn surface of the brake block after $50 \mathrm{~s}$ of sliding (the arrow indicates the sliding direction). The dark areas are worn.

intensively because there is no contact between the central part of the brake block and the wheel. The wavy feature of the upper curve can be attributed to the motion of the hotspots over the apparent contact area. The real contact occurs only in small spots in the apparent contact area, when these hot spots move due to wear and thermal expansion. The change in their distance from the thermocouples affects the measured temperature. The curve of the lower point is less wavy because the generated heat is less in this side. The temperature curve of the middle point shows no waviness because it is relatively far from the contact spots, so the motion of the hot spots has no significant effect.

Figure 5 shows the temperature development of the wheel. It can be seen that the temperature curve is rather linear.

\section{Numerical Modelling}

In order to understand the joint effect of wear and the thermal expansions on the contact of the brake block and the wheel, mechanical and thermal numerical simulations were performed.

The simulation process is shown in Figure 6. One cycle of the simulation can be divided into four main blocks.

First, a frictional contact FE calculation is run. In this phase, the brake block is pressed against the wheel, which is rotating at a constant rotational speed according to the measurement. Based on the contact pressure distribution determined by the first simulation block, a transient thermal FE calculation is performed next.

The frictional heat increment is determined for each contacting node, and the frictional heat values are applied as point flux type boundary conditions in the thermal FE model of the brake pad.

At the beginning of the simulation, room temperature was assumed at the entire model. In the later cycles, the initial 


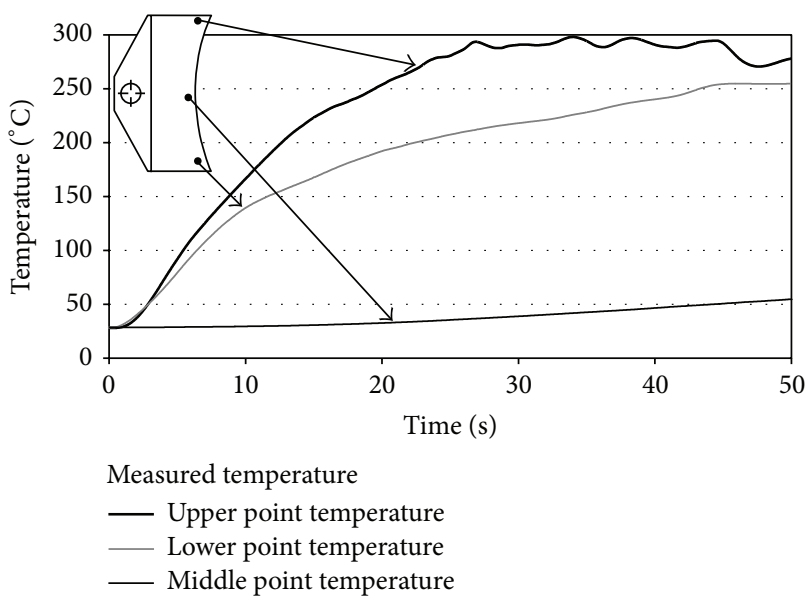

FIGURE 4: temperature at the measured points of the brake block.

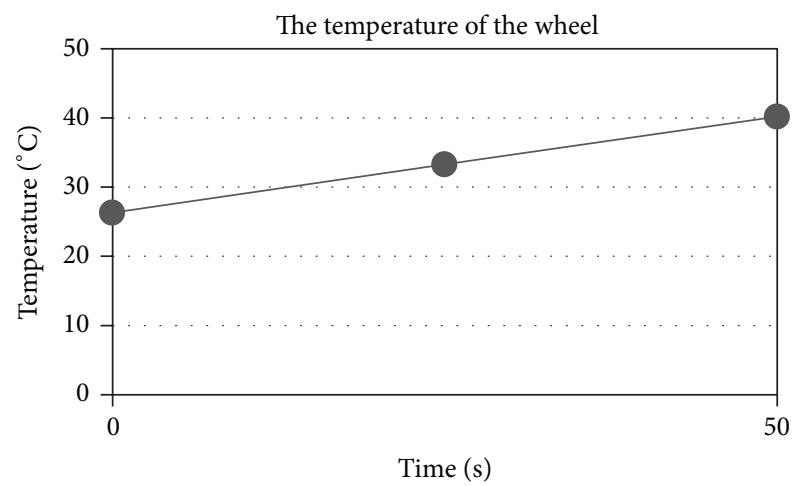

FIgURE 5: The temperature of the wheel versus time.

temperature distribution was obtained from the result of the previous thermal simulation.

In the next block, another FE contact calculation takes place, but now the effect of the thermal expansion is taken into account as well. In the last block of the cycle, we determine the nodal wear increments based on the contact pressure distribution evaluated by (1). Once the nodal wear increments are known, we move the contacting nodes according to them. The $\Delta h_{i}$ nodal wear of the $i$ th node in the contact area is defined as follows [12]:

$$
\Delta h_{i}=W_{s} p_{i} v \Delta t
$$

where $W_{s}$ is the specific wear rate, $p_{i}$ is the nodal contact pressure at node $i, v$ is the sliding velocity, and $\Delta t$ is the time increment.

In order to reduce the effects of the high peaks in the contact pressure distribution caused by the relatively high local temperatures in the contact zone, a smoothing procedure was applied. When a node is in contact, the neighbouring nodes were also moved according to the moving average contact pressure value of the patch around the node.
TABLE 1: Values of the temperature-dependent material properties.

\begin{tabular}{lcccc}
\hline$t\left({ }^{\circ} \mathrm{C}\right)$ & $E(\mathrm{GPa})$ & $\alpha(1 / \mathrm{K})$ & $c(\mathrm{~J} / \mathrm{kgK})$ & $\lambda(\mathrm{W} / \mathrm{mK})$ \\
\hline 0 & 103.00 & $1.01 E-05$ & 521.06 & 48.12 \\
25 & 102.31 & $1.03 E-05$ & 522.30 & 48.03 \\
100 & 100.08 & $1.07 E-05$ & 532.01 & 47.47 \\
200 & 96.76 & $1.12 E-05$ & 558.96 & 46.02 \\
300 & 93.04 & $1.18 E-05$ & 601.91 & 43.77 \\
400 & 88.92 & $1.23 E-05$ & 660.86 & 40.72 \\
500 & 84.40 & $1.29 E-05$ & 735.81 & 36.87 \\
600 & 79.48 & $1.34 E-05$ & 826.76 & 32.22 \\
700 & 74.16 & $1.40 E-05$ & 933.71 & 26.77 \\
800 & 68.44 & $1.45 E-05$ & 1056.66 & 20.52 \\
900 & 62.32 & $1.51 E-05$ & 1195.61 & 13.47 \\
1000 & 55.80 & $1.56 E-05$ & 1350.56 & 5.62 \\
\hline
\end{tabular}

The time increment of the simulation was $\Delta t=1 \mathrm{~s}$, so the total time of the experiment $(50 \mathrm{~s})$ was modelled in 50 simulation cycles.

3.1. The FE Model. The 3D FE model was created using the MSC.Marc software package. The same FE mesh was used in all of the four blocks of the simulation process. The brake block was modelled by 3918 8-node 3D elements of different size (Figure 7). Symmetry was considered in the model. In the contact calculations, the wheel was modelled as a rigid body, since the deformation of the wheel would not change the contact conditions significantly. The normal force was applied through a rigid shaft. A coefficient of friction with a value of 0.38 was prescribed between the brake block and the wheel. In the thermal calculations, a thermal face film boundary condition with a value of $20 \mathrm{~W} /\left(\mathrm{m}^{2} \mathrm{~K}\right)$ was applied for the surfaces of the brake block except for the symmetry plane, the contact zones, and the hole. On the surface of the hole, another thermal face film boundary condition with a value of $100 \mathrm{~W} /\left(\mathrm{m}^{2} \mathrm{~K}\right)$ was applied in order to approximately model the heat flow through the pin.

3.2. Frictional Heat Generation. The frictional heat generation was determined analytically as the following. The total heat power equals the work done by the friction force:

$$
Q=F_{\text {fr }} v=F_{\mathrm{n}} \mu v,
$$

where $F_{\mathrm{fr}}$ is the friction force, $F_{\mathrm{n}}$ is the normal force, $\mu$ is the coefficient of friction, and $v$ is the sliding velocity.

The total heat is distributed between the two contacting bodies. It was found earlier in $[13,14]$ that the larger part of the heat is conducted by the wheel. The ratio of the heat partition is found to be changing over the time [15]. However, a ratio of 


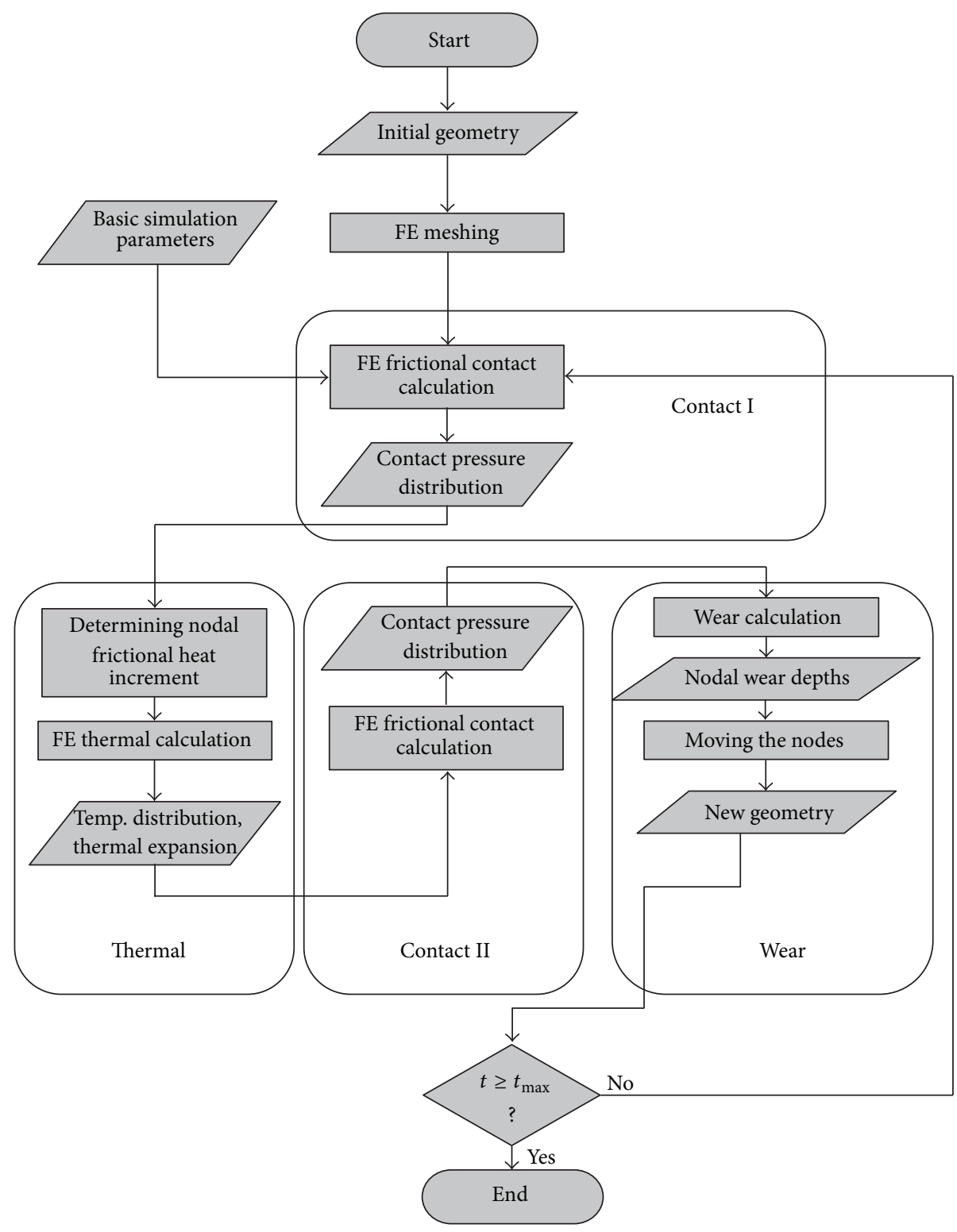

Figure 6: The flowchart of the simulation process.

heat partition $\left(K_{\mathrm{hp}}\right)$ with constant value was assumed in the series of calculations. The total heat is as follows:

$$
Q=Q_{\text {wheel }}+Q_{\text {block }}=\left(1-K_{\mathrm{hp}}\right) Q+K_{\mathrm{hp}} \mathrm{Q}
$$

where $K_{\mathrm{hp}}$ is the ratio of heat partition representing the block side.

In the FE calculations, the following material properties were assumed to model the cast iron (P10) material of the brake block:

(i) Poisson's ratio: $v=0.25$,

(ii) density: $\rho=7150 \mathrm{~kg} / \mathrm{m}^{3}$,

(iii) Young's modulus: $E=-0.00002 T^{2}-0.0272 T+103$, (iv) linear thermal expansion coefficient: $\alpha=0.55 E-$ $08 T+0.00001014$

(v) specific heat: $c=0.0008 T^{2}+0.0295 T+521.06$,

(vi) thermal conductivity: $\lambda=0.00004 T^{2}+0.0025 T+$ 48.115 ,

(vii) ratio of heat partition: $K_{\mathrm{hp}}=0.25$.

The values of these temperature dependent material properties for different temperatures are shown in Table 1.

\section{Results of the Simulation}

Figure 8 shows the calculated wear distribution of the brake block after $50 \mathrm{~s}$ of sliding. It can be seen that the wear is asymmetric as it was in the experimental results. The left side 


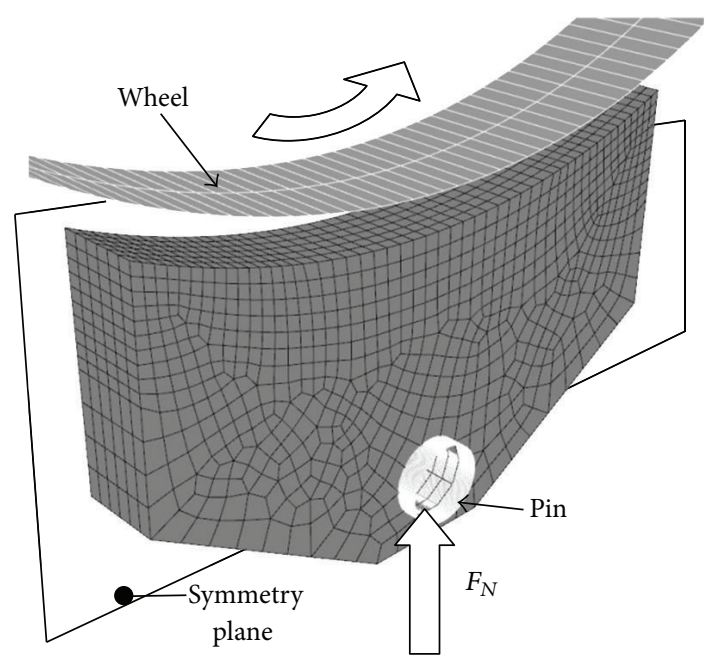

FIGURE 7: The FE mesh of the brake block with the wheel and the pin considered as rigid bodies.

of the brake block suffered more wear than the right side. On the other hand, the wear intensity does not differ significantly along the axial direction, which again is in accordance with the experimental test results. The quantitative comparison of the test and the simulation results shows slight differences. The worn areas of the experiment are approximately $14 \mathrm{~mm}$ and $10 \mathrm{~mm}$ long, while, in the simulation, those are $12 \mathrm{~mm}$ and $9 \mathrm{~mm}$, respectively.

The temperature of the nodes in the FE model that were in the position of the thermocouples of the test was obtained from the simulation result files. The calculated temperature curves of the three measured points of the brake block are shown in Figure 9. The temperature of the upper point is the highest; the temperature of the lower point is slightly lower. It can be seen that the calculated and the measured curves are in good agreement; however, the calculated curves near the edges show a wavier feature than those of the measurement. The temperature values of the three measured points of the test and the calculation are in good agreement.

Figure 10 shows the temperature distribution of the brake block at the end of the simulation. One can see that the parts near the edges of the contact area have the highest temperature. On the top, cylindrical face high-temperature spots are visible due to the spot-like contact of the last simulation cycle. The lowest temperature appears around the hole, where the heat flow through the pin was considered.

In order to better understand the physical processes, the simulation was extended for an additional $40 \mathrm{~s}$. Figure 11 summarizes the contact stress distributions of the contact face at the beginning and after 10, 30, 50, 70, and $90 \mathrm{~s}$ of sliding. It can be seen that, in the beginning, the two edges of the brake block were in contact. Later, the contact takes place in spots, which move cycle by cycle as the geometry changes due to wear and thermal expansion.

Figure 12 shows the temperature distribution on the sliding surface of the brake block during the simulation. One can compare the curves of Figures 11 and 12 and see

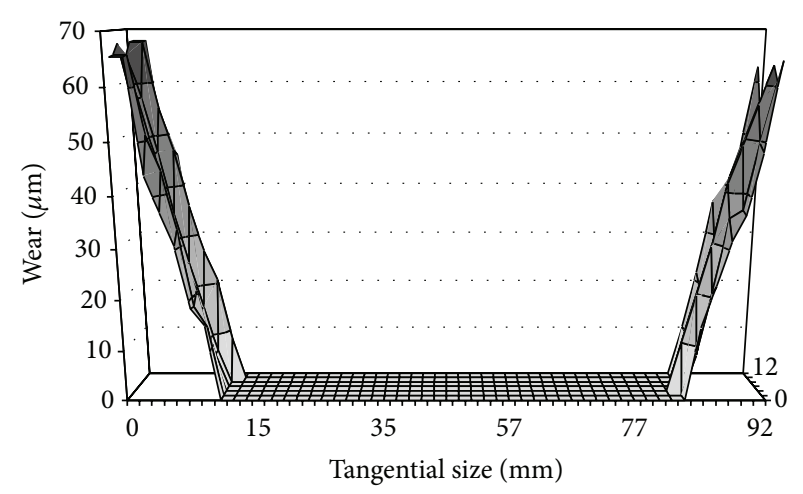

FIGURE 8: Calculated wear distribution after $50 \mathrm{~s}$ of sliding.

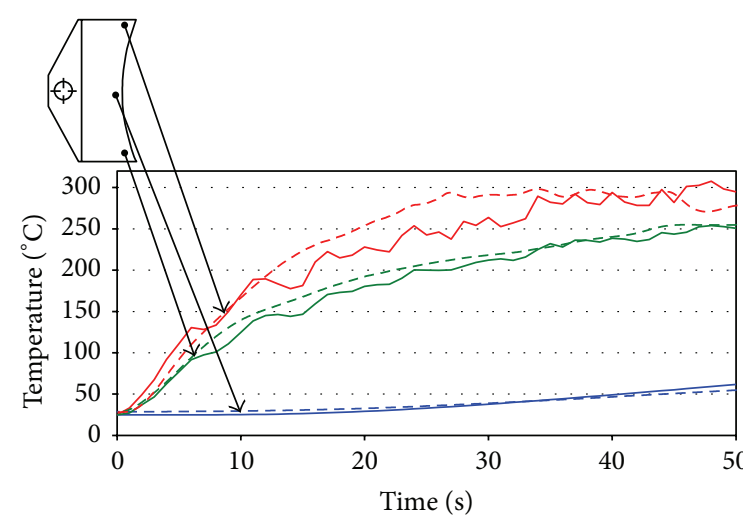

Temperature of the brake block

_ Upper point simulation

— Middle point simulation

_ Lower point simulation

- - - Upper point measurement

- - - Middle point measurement

- - - Lower point measurement

Figure 9: The calculated and measured temperatures of the three measured points versus time.

that the locations near the contacting spots have a high peak in the temperature distribution, since the friction heat is proportional to the contact pressure. It can be observed that the contact zones are moving from the initial position on the edges to the middle at first but then moving to the edges again. This can be explained by the following: consider one peak where the brake block contacts the rotating wheel. The contact spot has a peak in the contact pressure distribution, so the evolving frictional heat will cause a relatively high temperature at that location. The thermal expansion increases the contact pressure of this spot because of the high temperature. This area will suffer the highest wear, and the load will be shifted to the areas next to this spot (see the $30 \mathrm{~s}$ and the $50 \mathrm{~s}$ curves in Figure 11). This motion of the contact zones and the temperature peaks causes the wavy feature of the temperature curves in the measured points because the distance between the heat sources and the measured points is changing. 


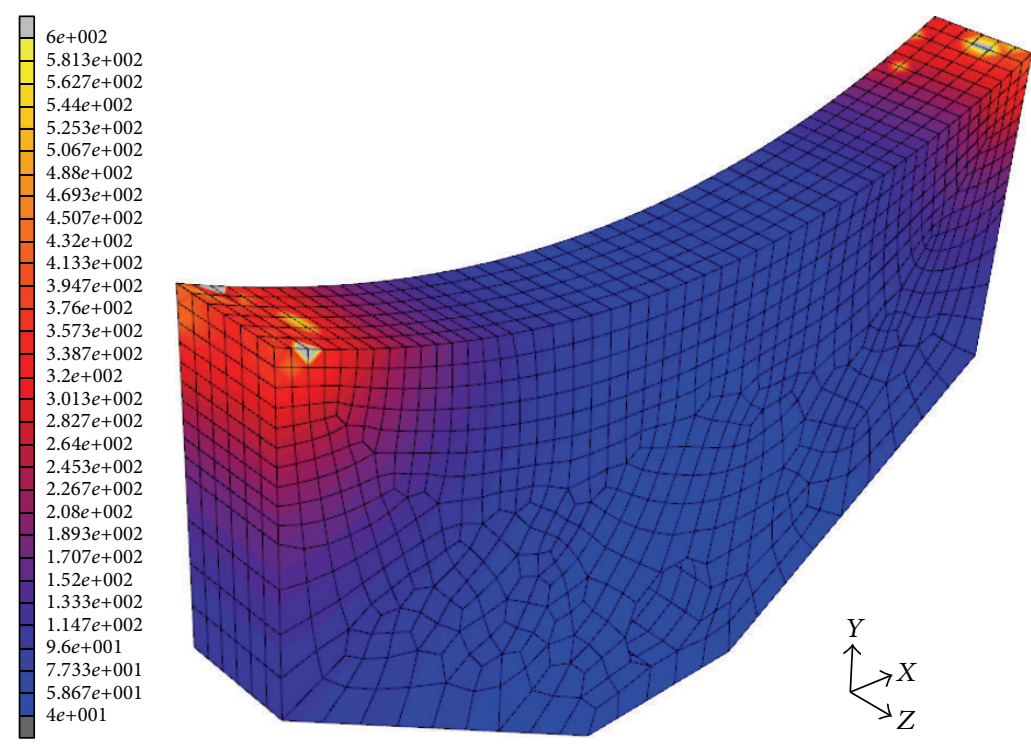

Figure 10: Temperature (in ${ }^{\circ} \mathrm{C}$ ) distribution of the brake block at the end of the simulation $(50 \mathrm{~s})$.

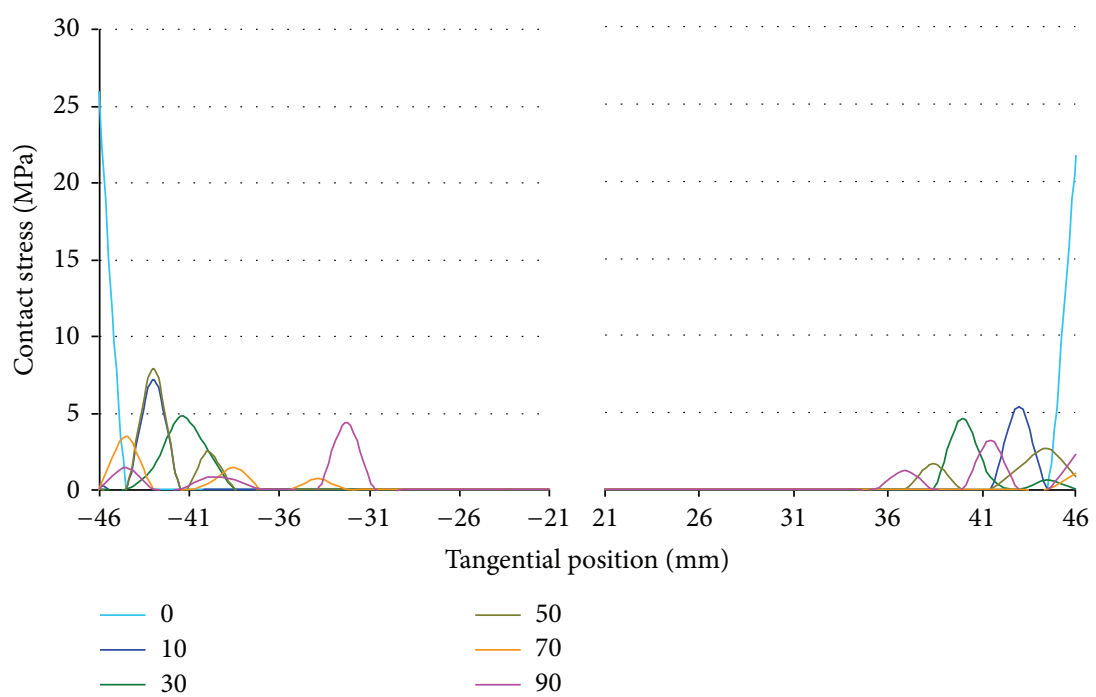

FIGURE 11: Contact stress distribution at the beginning and after 10, 30, 50, 70, and $90 \mathrm{~s}$ of sliding (averaged along the axial direction).

\section{Conclusions}

The braking process of a railway brake block and wheel was investigated experimentally and numerically. The phenomenon known as the motion of hot spots was observed in the experimental test. A coupled numerical contact-thermalwear simulation method was developed and applied in order to model the physical processes occurring during braking. In the cycles of the simulation, the frictional heat generation was determined based on the frictional contact calculation, and then the thermal expansions were calculated by the thermal calculation. In the last part of the simulation, the wear increments were determined, and the nodes were moved, and the new cycle was started with the new geometry. The same FE mesh was used in the different aspects of the simulation process. The wear and the temperature distribution of the calculation and the experimental test results were mostly similar.

The nonuniform wear process caused by the thermal expansion of the contacting "hot spots" was modelled.

\section{Conflict of Interests}

The authors do not have any conflict of interests with the content of the paper. 


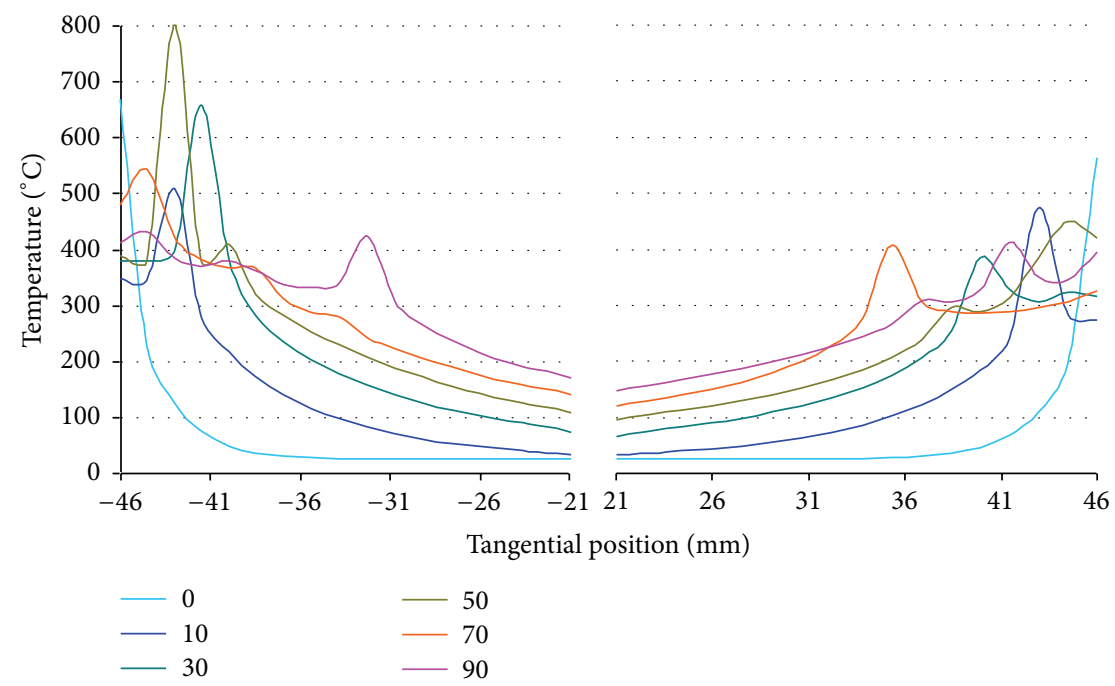

FIgURE 12: Temperature distribution on the surface at the beginning and after 10, 30, 50, 70 and $90 \mathrm{~s}$ of sliding (averaged along the axial direction).

\section{Acknowledgments}

The authors are thankful to the coworkers of the Department of Railway Vehicles and Vehicle System Analysis for their help in the experimental work, especially to Professor András Szabó and to Professor István Zobory. The work reported in the paper has been developed in the framework of the Project "Talent care and cultivation in the scientific workshops of BME." This Project is supported by the Grant TÁMOP 4.2.2.B-10/1-2010-0009.

\section{References}

[1] B. Czél, K. Váradi, A. Albers, and M. Mitariu, "FE thermal analysis of a ceramic clutch," Tribology International, vol. 42, pp. 714-723, 2009.

[2] Z. Lestyán, K. Váradi, and A. Albers, "Contact and thermal analysis of an alumina-steel dry sliding friction pair considering the surface roughness," Tribology International, vol. 40, pp. 982994, 2007.

[3] N. Fillot, I. Iordanoff, and Y. Berthier, "Simulation of wear through mass balance in a dry contact," Journal of Tribology, vol. 127, no. 1, pp. 230-237, 2005.

[4] I. Páczelt and Z. Mróz, "Variational approach to the analysis of steady-state thermo-elastic wear regimes," International Journal for Numerical Methods in Engineering, vol. 81, no. 6, pp. 728-760, 2010.

[5] A. Eleöd, "Numerische tribologie: strukturveränderungs- und verschlei $\beta$-simulation mit Hilfe der finiten elemente methode," Tribologie Und Schmierungstechnik, vol. 55, no. 3, pp. 17-22, 2008.

[6] L. Kónya and K. Váradi, "Wear simulation of a polymersteel sliding pair considering temperature- and time-dependent material properties," in Tribology of Polymeric Nanocomposites, vol. 55 of Tribology and Interface Engineering Series, chapter 7, pp. 130-145, 2008.

[7] M. Eltoukhy and S. Asfour, "Braking process in automobiles: investigation of the thermoelastic instability phenomenon," in
Modelling and Simulation, G. Petrone and G. Cammarata, Eds., I-Tech Education and Publishing, 2008.

[8] T. Vernersson, "Thermally induced roughness of tread braked railway wheels. Part 2: Modelling and field measurements," Wear, vol. 236, no. 1-2, pp. 106-116, 1999.

[9] S. H. Ahn and Y. H. Jang, "Frictionally excited thermoelastoplastic instability," Tribology International, vol. 43, no. 4, pp. 779-784, 2010.

[10] M. Ciavarella, L. Johansson, L. Afferrante, A. Klarbring, and J. R. Barber, "Interaction of thermal contact resistance and frictional heating in thermoelastic instability," International Journal of Solids and Structures, vol. 40, no. 21, pp. 5583-5597, 2003.

[11] D. Majcherczak, P. Dufrenoy, and Y. Berthier, "Tribological, thermal and mechanical coupling aspects of the dry sliding contact," Tribology International, vol. 40, no. 5, pp. 834-843, 2007.

[12] P. Pödra and S. Andersson, "Simulating sliding wear with finite element method," Tribology International, vol. 32, pp. 71-81, 1999.

[13] G. Fekete and K. Váradi, "Thermal FE analysis brake block test equipment, (Part 1)," Periodica Polytechnica-Mechanical Engineering. In press.

[14] G. Fekete and K. Váradi, "Thermal FE analysis brake block testequipment, (Part 2)," Periodica Polytechnica-Mechanical Engineering. In press.

[15] B. Liktor and K. Váradi, "Thermal analisys of a brake block model,” GÉP, vol. 63, pp. 67-70, 2012 (Hungarian). 

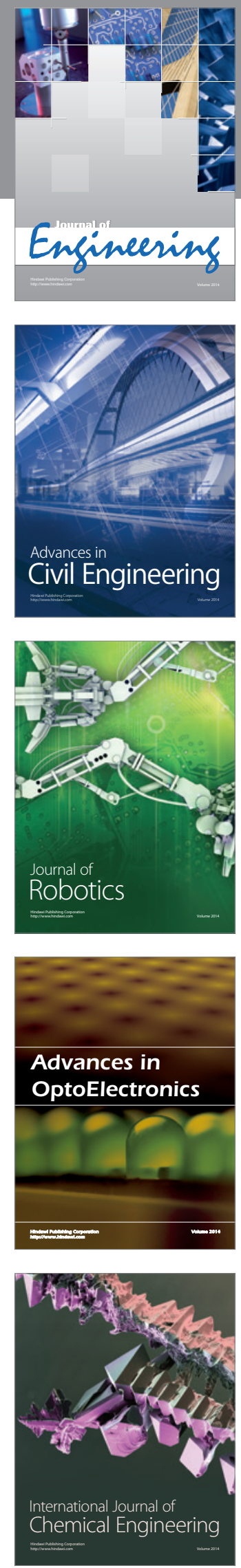

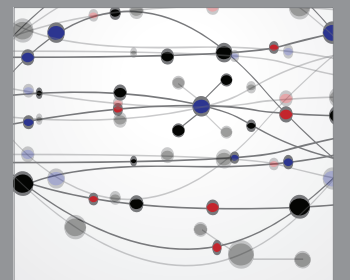

The Scientific World Journal
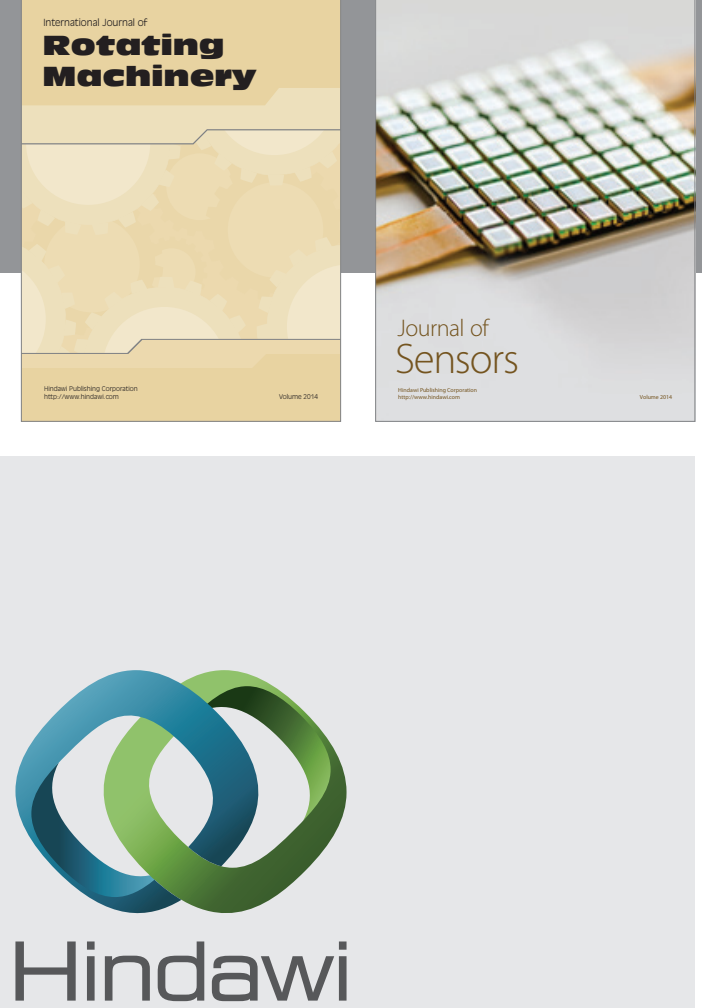

Submit your manuscripts at http://www.hindawi.com
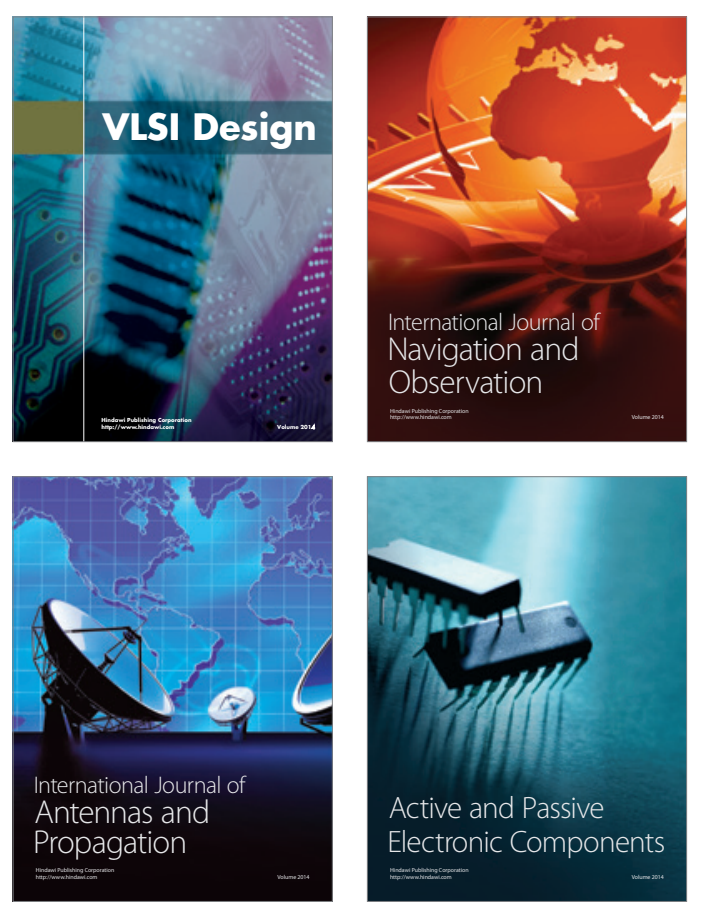
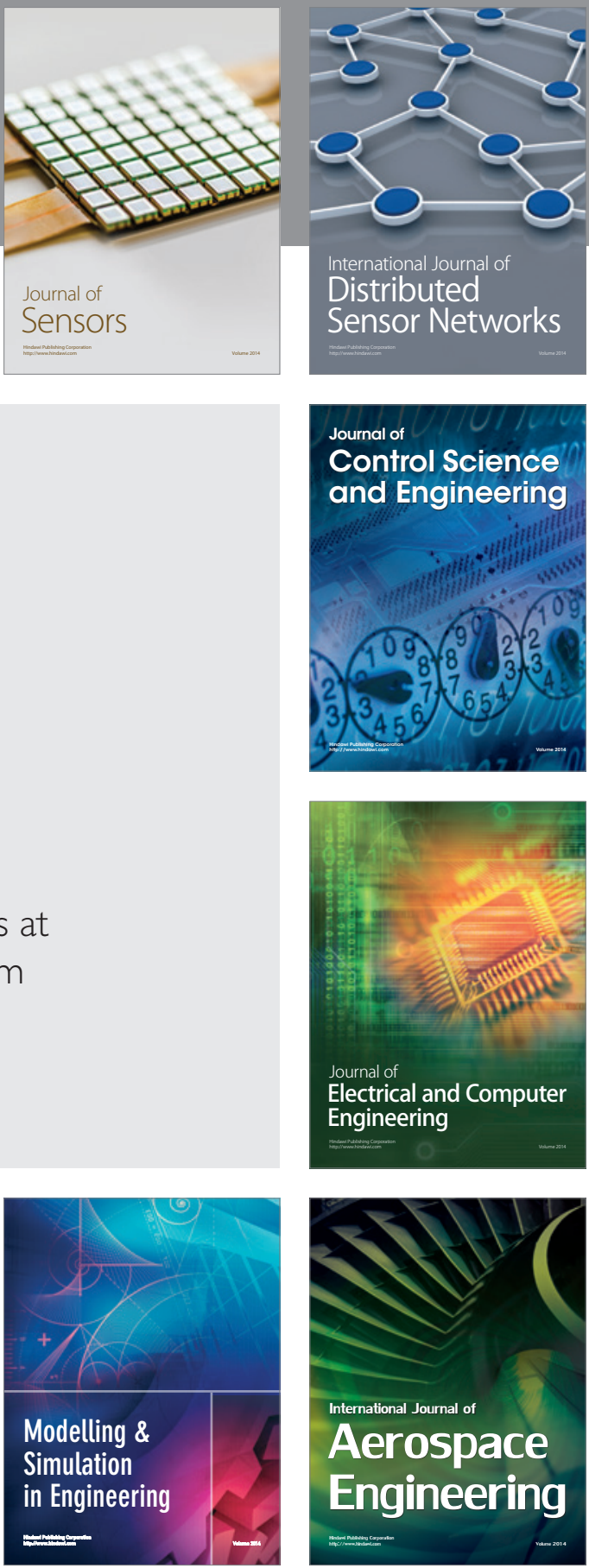

Journal of

Control Science

and Engineering
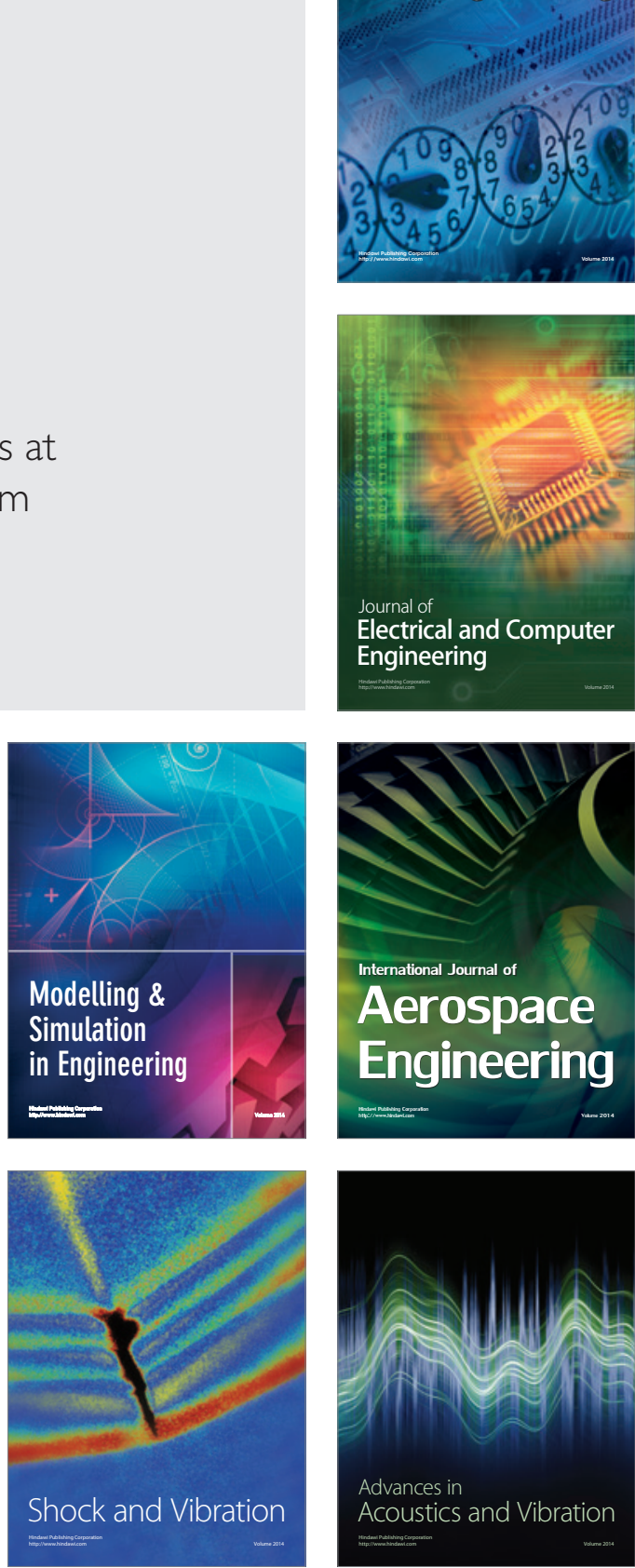